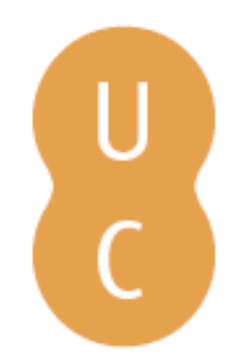

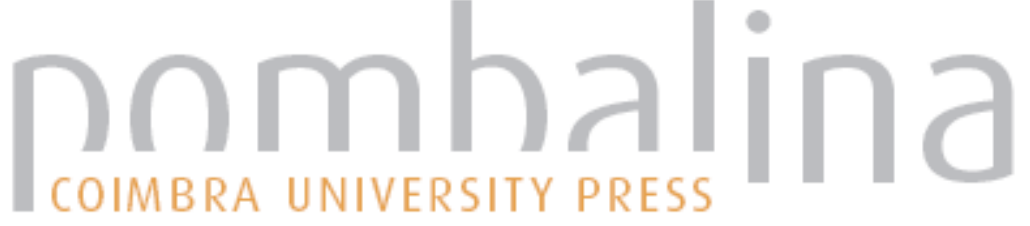

\section{A Investigação em música no ensino superior}

\author{
Autor(es): $\quad$ Carvalho, Mário Vieira de
}

Publicado por: Imprensa da Universidade de Coimbra

URL

persistente: $\quad$ URI:http://hdl.handle.net/10316.2/30046

DOI: $\quad$ DOI:http://dx.doi.org/10.14195/978-989-26-0567-8_16

Accessed : $\quad$ 26-Apr-2023 09:36:04

A navegação consulta e descarregamento dos títulos inseridos nas Bibliotecas Digitais UC Digitalis, UC Pombalina e UC Impactum, pressupõem a aceitação plena e sem reservas dos Termos e Condições de Uso destas Bibliotecas Digitais, disponíveis em https://digitalis.uc.pt/pt-pt/termos.

Conforme exposto nos referidos Termos e Condições de Uso, o descarregamento de títulos de acesso restrito requer uma licença válida de autorização devendo o utilizador aceder ao(s) documento(s) a partir de um endereço de IP da instituição detentora da supramencionada licença.

Ao utilizador é apenas permitido o descarregamento para uso pessoal, pelo que o emprego do(s) título(s) descarregado(s) para outro fim, designadamente comercial, carece de autorização do respetivo autor ou editor da obra.

Na medida em que todas as obras da UC Digitalis se encontram protegidas pelo Código do Direito de Autor e Direitos Conexos e demais legislação aplicável, toda a cópia, parcial ou total, deste documento, nos casos em que é legalmente admitida, deverá conter ou fazer-se acompanhar por este aviso.

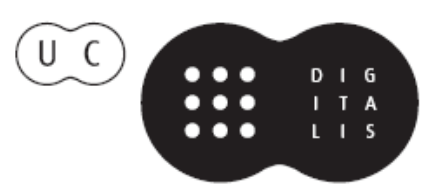




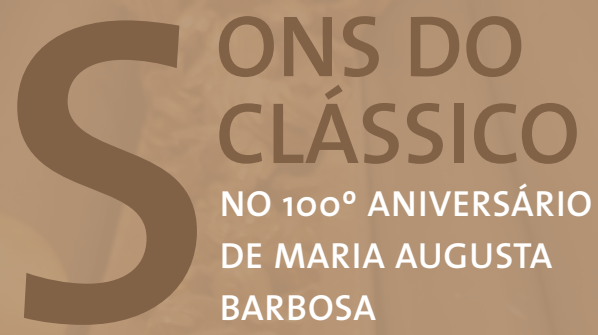

J. M. Pedrosa Cardoso

Margarida Lopes de Miranda COORDENAÇÃO 
Mário Vieira de Carvalho

Universidade Nova de Lisboa

\section{A INVESTIGAÇÃO EM MÚSICA NO ENSINO SUPERIOR ${ }^{129}$}

Em 2001 publiquei na Revista da Faculdade de Ciências Sociais e Humanas um extenso artigo, intitulado "As ciências musicais na transição de paradigma", no qual procedia a uma reflexão crítica retrospectiva sobre as ciências musicais e as suas diferentes sistematizações. Retomo aqui apenas algumas ideias desse texto, como introdução às questões que vos quero colocar.

A investigação em música não se esgota na musicologia ou nas ciências musicais, mas parece-me incontornável começar por discutir o momento fundador que está na origem da sua organização no ensino superior. Refiro-me à Universidade de Viena e à sistematização das Ciências Musicais por Guido Adler.

Em 1885, Adler partia da dicotomia clássica entre ciência histórica e ciência sistemática tomada a outras disciplinas (designadamente às ciências jurídicas, que lhe eram familiares). A perspectiva da história (ou diacrónica) baseava-se no método ideográfico; a perspectiva das ciências da natureza (sincrónica) baseava-se no médodo nomológico. Aquela debruçava-se sobre o peculiar, o singular, o evento situado no tempo e no espaço (o «acontecimento histórico»). Esta ocupava-se (em regra) do repetível, do ocorrente segundo determinadas leis, do mensurável (cf. Karbusicky, 1979: 17).

No enunciado de Adler, a musicologia como ciência histórica tinha por objecto a história $d a$ música «segundo as épocas, povos, impérios, nações, regiões, escolas artísticas, artistas». Enquanto ciência sistemática, visava «o estabelecimento das leis supremas que regem os ramos singulares da arte dos sons [Tonkunst]».

129 Comunicação ao Encontro Nacional de Investigação em Música, Porto, Casa da Música, 25-27 de Novembro de 2011. 
A sistematização de Adler reflectia, naturalmente, o paradigma da ciência moderna, o seu ponto de vista universalista e fundado numa epistemologia pretensamente imune ao senso comum. Mas hoje salta imediatamente à vista o seu carácter local.

A visão científica de Adler decorria do seu mundo musical: o mundo da música germânica e, especialmente vienense, desde o fim do século xviII. Importa enfatizar a distinção subtil que ele fazia entre, por um lado, a música, objecto da abordagem histórica e, por outro, a arte dos sons, objecto da abordagem sistemática. Eis aqui uma hierarquia implícita, que já tinha sido antes acolhida por Hegel e Hanslick. Se a tivermos em conta, então percebemos melhor o «sistema» de Adler:

- o objecto da musicologia histórica era a narrativa diacrónica da transformação da música em «arte dos sons»;

- apurada a «arte dos sons» (Tonkunst), competia à musicologia sistemática enunciar as "leis supremas" que a regiam (leis, em rigor, atemporais e universais, não relativizadas ou relativizáveis contextualmente).

A Tonkunst (isto é, a arte musical germânica e vienense da modernidade vivida por Adler) aparecia pois aqui como telos da música (Riethmüller, 1985: 71). A história captava a progressão da música até ao estádio de "arte dos sons", isto é, ao estádio em que era possível passar ao "enunciado das leis supremas do belo", que era objecto da Estética como disciplina sistemática.

Esta narrativa diacrónica era completada pela narrativa sincrónica que permitia distinguir a "arte dos sons» de outros fenómenos ou práticas musicais europeus ou extra-europeus que com ela coexistiam no presente. Tal era o objecto da disciplina sistemática a que Adler chamava Musikologie, que deu origem à Vergleichende Musikwissenschaft e depois à Etnomusicologia.

Finalmente, havia que transformar as «leis supremas do belo» nos enunciados normativos da pedagogia e da didáctica, também disciplinas sistemáticas, assegurando ad aeternum a reprodução "do belo musical».

O sistema não podia ser mais coerente e perfeito. O problema é que, justamente na altura em que Adler o gizava, já o movimento da história o punha 
fortemente em causa. A relação entre «teoria» e sua "aplicação» prática começara a ser abalada pelo processo de dissolução do sistema tonal. Por volta de 1900 estabelecia-se, também na música, a «institucionalização da anomia", com antecedentes na arte europeia desde meados do século xıx (Bourdieu, 1987: 255ss.). A «transvaloração de todos os valores» (Umwertung aller Werte), na formulação de Nietzsche, atingia, aliás, a sociedade e as estratégias de vida no seu todo. Uma estética normativa tornara-se inviável.

Não admira, por isso, que outras sistematizações se tivessem seguido às de Adler e que a noção de historicidade na abordagem da música ganhasse terreno. Contudo, em 1971, Carl Dalhaus ainda sentia a necessidade de propor a superação da fronteira rígida entre a perspectiva histórica e a sistemática, bem como, do mesmo passo, a distinção entre método ideográfico e método nomológico. Para Dahlhaus, "a verdadeira contrapartida da história da música» era representada por ciências como a psicologia da música, a teoria da música e a sociologia da música». Estas seriam uma espécie de disciplinas intermédias, de charneira, cujo método nem era nomológico, nem ideográfico. (Dahlhaus, 1971: 128).

Ainda assim, num artigo publicado na International Review of Aesthetics and Sociology of Music, fundada em 1970 pelo musicólogo croata Ivo Supicic, o mesmo Dahlhaus contestava a possibilidade de «a obra de arte musical» poder ser objecto da sociologia da música. Ou seja: apesar de reconhecer a necessidade de superação da sistematização de Adler, o próprio Dahlhaus permanecia arreigado a um dos princípios que a tinham inspirado: a distinção de base entre o que era arte e o que não era arte. Princípio que continuaria a marcar o ensino e a investigação musicológicas.

Superado o mito das «leis supremas do belo», o interesse pela abordagem histórica da criação musical europeia passara a predominar em absoluto, como Karbusicky (1979) verificou no estudo comparativo que empreendeu sobre os curricula universitários na década de 70. A «história da música» ou «musicologia histórica» tornara-se a ciência musical por excelência, empurrando as outras disciplinas para a marginalidade.

Entretanto, a distinção entre o estudo da "arte dos sons» europeia, reservado à musicologia histórica, e o estudo das culturas musicais tradicionais e/ou extra-europeias, reservado à etnomusicologia, traduzia-se na separação 
dos respectivos curricula e institutos de ensino e investigação, em mundos académicos isolados um do outro. Como já tenho referido noutras ocasiões, dir-se-ia que a etnomusicologia - e, portanto, a abordagem sociológica ou antropológica - era quase exclusivamente reservada ao estudo do "Outro inferior»: aquele que ainda não acedera supostamente nem ao conhecimento científico, nem à maturidade artística.

No meu texto de 2001 já mencionado, chamei também a atenção para a crítica pioneira de Charles Seeger (1935, 1951), uma das mais consequentes no diagnóstico das dificuldades legadas pelo sistema de Adler. A sua visão surpreende pelo engenho com que procura combinar três entrecruzamentos distintos no estudo da música:

1 entrecruzamento de dois pontos de vista: o "ponto de vista musical» propriamente dito e o "ponto de vista geral» ("não musical» ou "extra-musical»);

2 entrecruzamento de duas orientações: a «orientação sistemática» e a "orientação histórica»;

3 entrecruzamento de dois métodos: o «método científico» e o «método crítico».

Seeger (ao contrário de Adler) não estabelecia um elenco de disciplinas, mas postulava dir-se-ia o mais largo espectro de interdisciplinaridade possível a partir destes entrecruzamentos "que devia servir de base para a descrição de qualquer música com o máximo de objectividade».

No entanto, a preocupação de sistematizar era por ele tão longe levada, a sua visão sistemática totalizante era de tal modo ambiciosa, que as operações previstas no seu apparatus acabavam por rigidificar paradoxalmente as fronteiras entre o «musical» e o "extra-musical», entre o "histórico» e o "sistemático".

Numa aproximação ulterior ao problema, incluída na sua colectânea de ensaios publicada em 1977, Seeger (1970: 108) procurou aperfeiçoar a sua tentativa "de definição abrangente», isto é "totalizante» da musicologia. Passou a falar então de seis universos:

1 A musicologia era um estudo discursivo [a speech study], ao mesmo tempo sistemático e histórico, crítico e científico; 
2 O campo da musicologia era "a música total do ser humano, tanto em si mesma como nas suas relações com o que ela não era em si mesma»;

3 O exercício da musicologia cabia a estudiosos individuais, que podiam ver o campo dela, ou como músicos, ou como especialistas não musicais dentro de cujos campos alguns aspectos da música eram considerados como factos dados;

4 O objectivo da musicologia era a compreensão do ser humano, quer enquanto cultura humana...

5 ...quer na relação do ser humano com o universo físico.

A estes cinco "universos", cada um dos quais, inter-relacionado com todos os outros, juntava-se um sexto:

6 O universo do valor [value], conceito estrutural que consistia em operações de avaliação recíproca entre os diferentes universos. As conexões entre estes não eram apenas factuais, decorriam também de estratégias de avaliação. O discurso era a instância de integração de "facto" e "valor» (Seeger, 1970: 118 ss.).

Mais importante do que a pretensão totalizante da sistematização de Seeger e, de certo modo, em contra-ciclo com a mesma, é, porém, uma nova dimensão que ele introduz: a de questionar a musicologia como "prática para si». Ou seja, Seeger já parece partilhar de uma atitude de hermenêutica crítica da epistemologia, no sentido precisado por Boaventura Sousa Santos (1989: 28 ss.): o de responder à crise do paradigma da ciência moderna com o princípio geral de que «o objectivo existencial da ciência está fora dela»: é o humano.

Contudo, mesmo na reformulação dos anos 70, Seeger continua a não contemplar, por exemplo, a relevância intramusical do social como objecto da musicologia. A noção de «universo» inter-relacionável com outros «universos» não andava longe, porém, da tentativa de Kluge e Kaden, nos finais da década de 70, de superar a oposição entre orientação histórica e orientação sistemática através duma abordagem sistémica aberta, que põe em evidência as conexões estruturais entre diferentes áreas do social e do humano na sua 
interacção com os processos naturais (cf. Kluge 1977; Kaden, 1984, 1987). "Sistema» é entendido aqui, não como um conceito oposto ao de evolução ou desenrolar no tempo, mas sim como unidade de estrutura e processo, a qual não é resultado da mera cooperação ideal entre dois tipos de abordagem, antes é qualidade ou propriedade material dos fenómenos abordados. De "process-based systems thinking» como desafio aos limites da noção de estrutura, válido para os mais diversos campos científicos, falam nomeadamente Edwards e Jaros num artigo de 1994. Capra sublinha, por sua vez, em 1996, a relevância crescente do conceito de web of life ou networking nas ciências da natureza, porventura o contributo mais influente e de maior alcance do legado de Darwin, que se tornou mutatis, mutandis, não menos relevante para as ciências sociais. Web e networking são realidades que não podemos ignorar num mundo globalizado, onde todos se encontram conectados uns com os outros também via internet. "O real é relacional» - já o diziam Hegel e Bourdieu.

Podia citar ainda no mesmo sentido Joseph Kerman (1985), quando fez um historial das aporias em que se têm enredado diferentes escolas e tendências, designadamente nas áreas da história e da análise musicais, precisamente por não reconhecerem, à partida, a interdependência de factores e processos que a construção do objecto segundo esse modelo relacional poderia ajudar a surpreender e clarificar. Lembro, a propósito, que Kerman (ibid.: 73), compara a operação dos analistas que «removem a partitura, isolada, do seu contexto em ordem a examiná-la como um organismo autónomo" à operação que "remove um organismo da ecologia que o sustém». Noutro passo, Kerman (1985: 164), em crítica à tradição da musicologia histórica, conclui que «a famosa definição de Merriam» segundo a qual a etnomusicologia é "o estudo da música na cultura" tem o mérito de esclarecer o que o estudo da música não é: «não é o estudo da música ou músicas como estruturas ou sistemas autónomos». Neste sentido, critica Nattiez e outros que buscam a significação na imanência do texto, em vez de a procurarem na sua relação com as práticas sociais - aí convergindo com a viragem pós-estruturalista, na esteira de Wittgenstein, que acentuava o contexto dos usos da língua na significação. (Sobre essa viragem e as suas consequências para o estudo das artes em geral merece ser lembrado aqui um artigo de Anthony Giddens [1987]).

O pressuposto de que Kerman já partia era o da superação da dicotomia entre música e sociedade, já que também os processos musicais são 
necessariamente processos sociais. Nesse sentido, Adorno está mais perto de Merriam do que parece, na medida em que chama a atenção para a natureza social do material. Escalas, instrumentos, formas, técnicas de composição não são dados da natureza nem existem fora da sociedade. O material com que o músico trabalha é social e historicamente pré-formado. Por isso, para Adorno, a abordagem filosófica da obra é, simultaneamente, uma abordagem sociológica. Filosofia e sociologia tornam-se indestrinçáveis uma da outra. Eis o que se prende com o próprio conceito de teoria crítica.

A sociologia da música de Adorno incide tanto sobre a obra musical em si como sobre os contextos da criação, interpretação e recepção. Mas, em Adorno, a crítica da ideologia tem de ser uma crítica da linguagem. E a crítica da linguagem remete para a crítica da própria linguagem científica.

E eis como regressamos ao ponto de partida: o da crítica do cânone, o da necessidade de qualquer discurso científico se colocar a si próprio em questão, tal como é preconizado, em especial, para as ciências sociais por Immanuel Wallerstein, no relatório Para Abrir as Ciências Sociais (1996) que lhe foi encomendado pela Fundação Gulbenkian.

Devo a esta obra de Wallerstein o impulso para a posição que defendi no ano seguinte, em 1997, na mesa redonda sobre Musicologia e Sociologia realizada no âmbito do XVI Congresso da Sociedade Internacional de Musicologia, em Londres, subordinado ao tema "A musicologia e as disciplinas irmãs» (as comunicações das mesas-redondas foram recolhidas e publicadas por David Greer na Oxford University Press em 2000). Apontei então como principal tarefa da Sociologia da Música a de se constituir como uma "musicologia auto-crítica» ("Sociology of Music as Self-Critical Musicology») (Vieira de Carvalho, 2000). Isto é, defendi e defendo que a sociologia da música - em diálogo aberto com diferentes correntes do pensamento contemporâneo - tem de começar por questionar criticamente o conhecimento musicológico, incluindo o dela própria como disciplina científica.

Problematizar o discurso científico é colocar em questão tanto a tradição da musicologia histórica como a da etnomusicologia. Quanto à musicologia histórica, importa questionar a ideologia da objectividade que nela ainda está instalada e continua a servir de bandeira mesmo aos investigadores mais jovens - objectividade entendida como conhecimento da música em 
si, a partir de uma perspectiva em que o investigador é suposto ser imune a contextos de espaço e de tempo, à política e às ideologias ("o acto político de despolitizar a música", e também a de a "disciplinar», para citar Bohlman [1993]). Quanto à etnomusicologia, o bloqueio tende (ou tendia) a ser para a reificação da metodologia - a crença num método que se crê adequado a qualquer situação ou processo musicais e que permitiria assegurar a posição neutral do investigador.

Ao problematizar a objectividade, como Wallerstein observa no seu relatório, não se trata de reduzir as ciências sociais "a uma miscelânea de perspectivas individuais", mas sim de submeter a investigação "ao juízo intersubjectivo" - excluindo, portanto, que qualquer dos interlocutores se sirva da «máscara da objectividade para levar por diante a sua visão subjectiva». "Empurrar" as ciências sociais "na direcção de um significativo grau de objectividade» consistiria, pois, segundo Wallerstein, em levá-las a adoptar "uma postura de inclusão (no que respeita ao recrutamento dos seus praticantes, à abertura a uma multiplicidade de experiências culturais, ao leque dos tópicos de estudo julgados legítimos)» e a privilegiar uma posição auto-reflexiva crítica: ter consciência de que "o conhecimento é socialmente construído" é o primeiro passo para produzir socialmente um conhecimento mais válido» (ibid.: 129s.).

Relativamente à problematização do método, os Elementos Filosóficos de uma Teoria da Sociedade de Adorno, publicados postumamente em 2008, nada perderam da sua actualidade. Adorno denuncia aí a "fetichização do conhecimento", que consiste em colocar o método no lugar da finalidade do conhecimento, isto é, levando a uma inversão dos meios e dos fins. Em alternativa à tendência para aperfeiçoar o método como se nada tivesse a ver com o objecto, propõe que se refinem os instrumentos científicos, agudizem os critérios, pondo à prova a validade das proposições científicas, na qual necessariamente intervém o próprio objecto estudado. Opõe ao pensamento dedutivo cartesiano, o pensamento indutivo de Bacon (Novum Organum, 1620), que já postulava a necessidade de questionar os critérios como “ídolos» enganadores que excluem como impossível aquilo que é ou pode ser parte do real. O problema epistemológico decisivo, para Adorno, está, portanto, na resistência da realidade à teoria. Daí a sua crítica à concentração no método, 
que impede a compreensão do objecto. ${ }^{130}$ Assim, em oposição ao mito da absoluta correcção da metodologia, que fetichiza a ciência e esteriliza o conhecimento crítico, Adorno reconhece que é, não raro, mais produtiva a abordagem imediata do objecto, a recuperação da espontaneidade naïve.

Trata-se de recuperar a capacidade de experiência não regulamentada e cultivar o achado ou a inspiração (Einfall), a espontaneidade, tal como na arte. Cultivar o achado ou a inspiração não invalida, contudo, a necessidade de os pôr à prova e submeter ao controlo da adequação ao objecto. O método carece de auto-problematização crítica, requerida pela própria necessidade de compreender o objecto. É necessária a mediação recíproca entre o conceito e a diversidade da experiência sensível.

Mas é ainda Adorno que me leva à última questão, antes de retirar de tudo isto algumas conclusões eventualmente úteis. Essa última questão é a da arte em si, ou da música em si, ela própria como conhecimento, como via de conhecimento autónomo, diferente do conhecimento científico. À força de querermos estudar e compreender a música submetendo-a à abordagem de um leque pluridisciplinar muito variado que vai desde a sua consideração como fenómeno físico-acústico à sua consideração como praxis social, passando por muitas outras dimensões (psicológicas, cognitivas, histórico-antropológicas, estéticas, etc., etc.), corremos o risco de subestimar o que ela própria nos pode proporcionar como actividade de conhecimento, isto é:

- não se trata apenas de compreender a música através da história, mas também de compreender a história através da música;

- não se trata de pensar a música na perspectiva da filosofia, mas também de abordar a música ela própria como filosofia;

- não se trata de interpretar a música segundo um quadro teórico-metodológico das ciências sociais, mas também de ela nos interpretar a nós e à

130 Para Adorno, é neste mesmo princípio que assenta o fundamento das nossas sociedades. Abstrai-se das qualidades e dos valores de uso específicos que as coisas em si tomam no seu relacionamento com as pessoas. Tudo é reduzido à forma de equivalência geral - ao valor de troca, um princípio de valor abstracto, separado do próprio objecto, princípio que, afirma ele, é replicado na ciência e na filosofia. Domina a razão instrumental ou a instrumentalização da razão. 
sociedade em que vivemos (como se a música também pudesse ser uma espécie de teoria social codificada em sons).

Ou seja: é preciso que a música não seja apenas objecto de conhecimento, mas também sujeito activo de conhecimento. Eis o que se procura contemplar hoje em dia na chamada "artistic research", conhecimento através das artes, da prática artística, daquilo que só estas podem proporcionar como abordagem do humano e do real, algo que não é comensurável ou traduzível em palavras ou pensamento discursivo.

Que poderíamos retirar daqui para a organização ou reorganização da investigação em música no ensino superior? Eis os pontos que ponho à discussão:

1 Abandonar de vez a ideia de um currículo de disciplinas fechado ou demasiado centrado num núcleo duro de disciplinas obrigatórias. Em cada estabelecimento de ensino superior, não se trata de clonar diplomados, mas sim de abrir as portas a perfis individuais de formação diferenciados.

2 Abandonar as grandes narrativas lineares que, na ânsia de preencherem todas as possíveis lacunas na transmissão de conhecimento, não fazem senão reduzi-lo a um conhecimento canónico, que exclui mais do que integra. Em cada área do saber o conhecimento totalizante é ilusório. Assumir a abordagem do fragmento, o estudo de caso, o problema ou o tópico específicos, a questão ou a pergunta a que pretendemos responder com um seminário - eis o que me parece mais produtivo para a formação dos estudantes, estimulando do mesmo passo a ligação entre ensino e investigação. Com os recursos hoje disponíveis via internet, menos ainda se justificam as grandes narrativas.

3 Em vez de predeterminar linhas de especialização mais ou menos compartimentadas, antes favorecer a sua emergência e diferenciação através da ars combinatoria de módulos ou unidades de formação. Não reduzir as ciências musicais (como até aqui, por exemplo, na FCSH) à pseudo-dicotomia entre "musicologia histórica» e "etnomusicologia», quando a Filosofia e a Estética musicais, a Sociologia da Música, a Psicologia e a Psicopedagogia musicais, 
os Estudos Cognitivos, os Estudos de Música Popular, de Globalização, Mass Media, Estudos Culturais, Estudos de Género, a chamada Investigação Artística ou Artistic Research (envolvendo não só Estudos de Composição e Performance, mas também as relações da música com a literatura e as outras artes), Música e Política, etc. etc. são igualmente susceptíveis de mobilizar recursos docentes e o empenho dos estudantes.

4 Acabar com os compartimentos estanques entre a via de formação artística e a via da formação musicológica. Promover a possibilidade de interpenetração de ambas.

5 Não coarctar drasticamente, como tem acontecido, as possibilidades de formação em áreas do conhecimento diferentes da música ou da musicologia como áreas principais. Favorecer a dinâmica dos majors e dos minors, permitindo muito maior peso da formação que pode ser obtida fora da área principal. Se não queremos formar músicos ou musicólogos que sejam clones uns dos outros, também não queremos que eles, ainda por cima, corram o risco de vir a ser Fachidioten (como dizem os alemães: especialistas idiotas). ${ }^{131}$ Mais interdisciplinaridade na formação não retira competências ao especialista na área principal. Pelo contrário, reforça-as. Um musicólogo que tenha uma forte componente em sociologia, ou em filosofia, ou em economia, ou em psicologia, ou em direito, ou em literatura, ou em cinema, ou em arquitectura, ou em engenharia, ou em biologia, etc., etc., obtida à custa de disciplinas de música/musicologia que tivesse de frequentar num currículo maximalista, não perde competências musicais/musicológicas, antes pelo contrário: fecunda-as, alarga-as, reforça-as. O cruzamento interdisciplinar permite-lhe apreender e reformular os problemas da música/musicologia sob uma nova perspectiva. Está mais apto a produzir conhecimento novo, em vez de reproduzir mais do mesmo. Está mais alerta relativamente à inércia do saber, que Bourdieu exprimiu num dito corrente no "Direito das Sucessões»: le mort saisit le vif (o morto toma conta do vivo que lhe aceita a herança).

131 Hoje há povos inteiros a sofrer na pele o erro de formar Fachidioten na economia. 
6 Opções científicas quanto às disciplinas a considerar são neste, sentido, opções ideológicas. Uma perspectiva inclusiva torna tão legítimo um seminário de "Música e Política» quanto um seminário sobre "Música barroca». Comecemos por não fazer da nossa própria disciplina a mais importante de todas, e pretender torná-la obrigatória. Temos de abandonar este pensamento. Há que definir, sim, módulos de formação, cada qual com um número variável de seminários, dentro dos quais o estudante deverá obter unidades de crédito. E depois deixar que o estudante combine esses módulos de acordo com as suas motivações e interesses, ora tomando a música/musicologia como área principal, ora como área complementar ou minor, e possa ir buscar as unidades de crédito restantes a módulos de outras áreas disciplinares. Na minha opinião, nenhuma licenciatura devia ter mais de 120 unidades de créditos em módulos relativos à área principal (2/3 do total). O restante terço devia poder ser consagrado pelo estudante a módulos de outras áreas (até 60 u. c.). Também nos mestrados a abertura interdisciplinar devia ser assegurada. E os próprios mestrados serem já, de raíz, diversificados: reflectindo o vasto leque de abordagens possíveis da música/musicologia.

7 O conceito que melhor define esta proposta de organização curricular é o conceito de rede: rede de possibilidades de formação, que deve ser oferecida aos estudantes que entram no ensino superior. Eles entram para uma escola, para um curso ou área de formação principal, mas devem ter à sua frente várias combinações em aberto, dentro e fora dessa escola, dentro e fora do país. E essa abertura não deve parar no primeiro grau. O segundo grau deve abrir ainda mais o leque das alternativas. O percurso curricular de cada estudante, em vez de pré-dado, tornar-se-á um processo emergente, a partir dessa rede de possibilidades de formação. 


\section{Referências}

Adler, Guido (1885), «Umfang, Methode und Ziel der Musikwissenschaft», Vierteljabrschrift für Musikwissenschaft, I, 1 (1885): 5-20.

Adorno, Theodor W. (2008), Philosophische Elemente eine Theorie der Gesellschaft (eds. Tobias ten Brink and Marc Phillip Nogueira), Frankfurt a.M.: Suhrkamp, 2008.

Bohlman, Philip V. (1993), "Musicology as a Political Act», in: The Journal of Musicology, XI/ 4 (1993): 411-436.

Bourdieu, Pierre (1987), O Poder Simbólico, Lisboa, Difel, 1989.

Capra, Fritjof (1996), The Web of Life. A New Scientific Understanding of Living Systems, New York: Anchor Books.

Dahlhaus, Carl (1974a), "Das musikalische Kunstwerk als Gegenstand der Soziologie», International Review of the Aesthetics and Sociology of Music, V (1974): 11-24.

Edwards, Lynn B., e Gyorgy G. Jaros (1994), «Processe-Based Systems Thinking Challenging the Boundaries of Structure", Journal of Social and Evolutionary Systems, 17/3 (1994): 339-353.

Giddens, Anthony (1987), "Structuralism, post-structuralism and the production of culture», Social Theory and Modern Sociology (do mesmo), Londres, Blackwell, 1993: 73-108.

Kaden, Christian (1984), Musiksoziologie, Berlin, Verlag Neue Musik.

Kaden, Christian (1987), «Systematische Musikwissenschaft» [entrada elaborada para uma nova edição remodelada do Dicionário de Música de Tomás Borba e F. Lopes--Graça, segundo uma concepção depois abandonada com a demissão do coordenador do projecto, Mário Vieira de Carvalho], ms.

Karbusicky, Vladimir (1979), Systematische Musikwissenschaft. Eine Einführung in Grundbegriffe, Methoden und Arbeitstechniken, Munique, Wilhelm Fink.

Kerman, Joseph (1985), Contemplating Music. Challenges to Musicology, Cambridge/ Massachusetts, Harvard University Press.

Kluge, Reiner (1977), "Auf dem Weg zu einer Systematischen Musikwissenschaft", Beiträge zur Musikwissenschaft, XIX (1977), 4: 3-16.

Merriam, Alan P. (1964), The Anthropology of Music, Evanston, Northwestern University Press.

Riethmüller, Albrecht (1985), «Stationen des Begriffs Musik», Geschichte der Musiktheorie, I (ed. Frieder Zaminer), Darmstadt, Wissenschaftliche Buchgesellschaft.

Seeger, Charles (1935), "Systematic and historical orientations in musicology", Acta Musicologica, XI (1939): 127-128.

Seeger, Charles (1951), "Systematic Musicology: Viewpoints, Orientations, and Methods», Journal of the American Musicological Society, IV, 3 (1951), 242-243. 
Seeger, Charles (1970), "Toward a Unitary Field Theory for Musicology", Studies in Musicology (1935-1975) (do mesmo), Berkeley, etc., University of California Press, 1977: 102-138.

Seeger, Charles (1977), "Systematic (synchronic) and historical (diachronic) orientations in Musicology", Studies in Musicology (1935-1975) (do mesmo), Berkeley, etc., University of California Press, 1977 : 1-15.

Sousa Santos, Boaventura de (1989), Introdução a uma Ciência Pós-Moderna, Porto, Afrontamento.

Vieira de Carvalho, Mário (2000) "Sociology of Music as Self-Critical Musicology", in: Musicology and Sister Disciplines - Past, Present, Future(ed. David Greer), Oxford, Oxford University Press, 2000: 342-366.

Vieira de Carvalho, Mário (2001), "As ciências musicais na transição de paradigma", in: Revista da Faculdade de Ciências Sociais e Humanas, 14 (2001): 211-233.

Wallerstein et al., Immanuel (1996), Para abrir as ciências sociais. Relatório da Comissão Gulbenkain sobre a reestruturação das Ciências Sociais, Lisboa, Europa-América. 